\title{
Changes in Interleukin 18 in the Retinas of Otsuka Long-Evans Tokushima Fatty Rats, a Model of Human Type 2 Diabetes
}

\author{
Noriaki Nagaii ${ }^{1}$, Yoshimasa Ito $^{1,2 *}$, Norio Okamoto ${ }^{3}$, Yoshikazu Shimomura ${ }^{3}$ and \\ Haruki Okamura ${ }^{4}$ \\ ${ }^{1}$ Faculty of Pharmacy and ${ }^{2}$ Pharmaceutical Research and Technology Institute, Kinki University, 3-4-1 Kowakae, Higashi-Osaka, Osaka, 577- \\ 8502, Japan \\ ${ }^{3}$ Department of Ophthalmology, Kinki University Faculty of Medicine, Osaka-Sayama, Osaka 589-8511, Japan \\ ${ }^{4}$ Institute for Advanced Medical Sciences, Hyogo College of Medicine, 1-1, Mukogawa-cho, Nishinomiya, Hyogo, 663-8501, Japan
}

\begin{abstract}
Recent findings have implicated the involvement of interferon- $\gamma$ (IFN- $\gamma)$, a part of the Th1 cytokine response, in the retinal inflammation of diabetic patients. In the present study, we investigate whether hyperglycemia relates to the expression of interleukin 18 (IL-18), and leads to the production of IFN- $\gamma$ in the retinas of Otsuka Long-Evans Tokushima Fatty (OLETF) rats, a model of type 2 diabetes mellitus. Plasma blood glucose, triglyceride and cholesterol levels in 60-week-old OLETF rats, in which the development of diabetes mellitus was observed, were significantly higher than in 60-week-old Long-Evans Tokushima Otsuka (LETO) rats used as normal controls. The expression levels of genes that cause IL-18 activation (IL-18, IL-18 receptor and caspase-1) in OLETF rats were increased at 60 weeks of age, and the levels of IL-18 and IFN- $\gamma$ in 60-week-old OLETF rat retinas were also higher than in 60-week-old LETO rats. Furthermore, IFN- $\gamma$ levels increased with increasing IL-18 levels in the retinas of OLETF rats, and a close relationship was observed between the levels of IL-18 and HbA1c. The rapid increase in plasma glucose levels following the oral administration of glucose solution $(3.0 \mathrm{~g} / \mathrm{kg})$ did not affect the IL-18 and IFN- $\gamma$ levels in the retinas of LETO rats, whereas the levels in the retinas of OLETF rats increased significantly. In conclusion, the expression of IL-18 is increased in the retinas of OLETF rats, and chronic hyperglycemia may accelerate the release of IL-18 and IFN- $\gamma$ from inflammatory cells in retinal blood vessel. It is possible that IFN- $\gamma$ production via IL-18 in the retinas of 60-week-old OLETF rats is caused by hyperglycemia, and plays a role in the inflammation of the OLETF rat retinas.
\end{abstract}

Key words: Interleukin 18 , retina, diabetes mellitus, interferon- $\gamma$, OLETF rat

\section{INTRODUCTION}

The prevalence of diabetes mellitus, a common metabolic disorder, is increasing rapidly. Currently, the disease affects more than 190 million people worldwide, and this number will continue to rise in the near future ${ }^{1,2)}$. Among the factors responsible for the increasing prevalence of diabetes mellitus are obesity, the consumption of energy-dense diets, and low levels of physical activity ${ }^{3)}$.

Diabetic retinopathy, one of the secondary complications of diabetes mellitus, is the leading causes of blindness in the industrialized world. There is emerging evidence to support the notion that inflammation in the retina, characterized by the activation of microglia and astroglia, is in- volved in the pathogenesis of diabetic retinopathy. Therefore, diabetic retinopathy is a chronic, low-grade inflammatory disease ${ }^{4-6)}$. Animal models, as well as clinical studies, have reported the idea that inflammation contributes to the development of diabetic retinopathy ${ }^{7,8)}$. Furthermore, increased leucostasis has been reported in the retinas of diabetic animals ${ }^{9)}$, along with an increased expression of intercellular adhesion molecule 1 (ICAM-1 ${ }^{10)}$ and platelet activation ${ }^{11)}$. Elevated levels of tumor necrosis factor alpha $(\mathrm{TNF}-\alpha)$ in epiretinal membranes have been reported in diabetic patients ${ }^{12)}$, together with increased levels of the proinflammatory cytokine interleukin(IL) $1 \beta$ in retinal cell cultures exposed to high glucose concentra-

\footnotetext{
*Correspondence to: Yoshimasa Ito, Faculty of Pharmacy and Pharmaceutical Research and Technology Institute, Kinki University, 3-4-1 Kowakae, Higashi-Osaka, Osaka, 577-8502, Japan

E-mail: itoyoshi@phar.kindai.ac.jp

Accepted February 13, 2013 (received for review October 31, 2012)

Journal of Oleo Science ISSN 1345-8957 print / ISSN 1347-3352 online

http://www.jstage.jst.go.jp/browse/jos/ http://mc.manusriptcentral.com/jjocs
} 
tions ${ }^{13,14)}$. In addition, various clinical and experimental studies have reported elevated concentrations of cytokines such as IL-8, IL-2, IL-1a IL-6, and interferon- $\gamma$ (IFN- $\gamma$ ) in serum, vitreous, aqueous humor, and epiretinal membrane samples from subjects with diabetic retinopathy ${ }^{15-21)}$. On the other hand, IL-18 also plays an important role in inflammatory action ${ }^{22,23)}$, and serum IL-18 concentrations are reported to be increased in individuals with human type 2 diabetes mellitus, in obese individuals, and in individuals with polycystic ovary syndrome ${ }^{24-26)}$. The infusion of glucose into normal volunteers and individuals with impaired glucose tolerance induces an acute increase in serum IL-18 concentrations ${ }^{27)}$. Furthermore, it has been reported that the expression of IL-18 mRNA in the retinas of streptozotocin-induced diabetic rats as an animal model for insulin-dependent diabetes mellitus is enhanced at 24 weeks after the onset of diabetes mellitus ${ }^{28)}$. However, to our knowledge, the effect of long-term (chronic) and acute hyperglycemia on IL-18 and IFN- $\gamma$ production in the retina in the case of non-insulin-dependent diabetes mellitus has not yet been reported, and its elucidation is important.

IL-18 is a pleiotropic cytokine belonging to the IL-1 family $^{22,23)}$. It is expressed as an inactive $24-\mathrm{kDa}$ proform that is cleaved by caspase-1 (IL-1 $\beta$ converting enzyme, a cystine protease) to an $18-\mathrm{kDa}$ active form ${ }^{22,23)}$. Released mature IL-18 exerts its effects upon binding to its cognate receptor (IL-18R ${ }^{29)}$. Two subunits of IL-18R have been characterized as belonging to the IL-1R family. An IL-1R related protein (IL-1Rrp or IL-1 R5) was identified as a lowaffinity receptor for IL-18 and renamed IL-18 $\mathrm{R}^{29)}$. The second subunit, IL-18R $\beta$ does not bind IL-18 directly, but the $\beta$ chain increases IL-18 binding affinity and is necessary for initiating signal transduction in target cells $^{30}$. The binding of mature IL-18 to IL-18R leads to the production of IFN- $\gamma^{31)}$.

In the present study, we determined the expression of IL-18 in in diabetes mellitus retinas using Otsuka Long-Evans Tokushima Fatty (OLETF) rats, a model of type 2 diabetes mellitus. In addition, we investigated whether hyperglycemia relates to the expression of IL-18 and IFN- $\gamma$ in the retinas of OLETF rats.

\section{EXPERIMENTAL}

\subsection{Animals}

Long-Evans Tokushima Otsuka (LETO)rat is widely used as a control rat of an OLETF rat (the food intake, water consumed, body weight, Glu, TG and Cho levels in LETO rats were similar to those in Wistar rats). Male LETO and OLETF rats at 10, 38 and 60 weeks of age were used in this study, and the LETO and OLETF rats were obtained from Otsuka Pharmaceutical Co., Ltd., and housed under standard conditions (12 h/d fluorescent light(07:00-19:00), $25^{\circ} \mathrm{C}$ room temperature) with free access to a commercial $\operatorname{diet}(\mathrm{CE}-2$, Clea Japan Inc., Tokyo, Japan) and water. All procedures were performed in accordance with the guidelines of the Kinki University Faculty of Pharmacy Committee for the Care and Use of Laboratory Animals and the Association for Research in Vision and Ophthalmology resolution on the use of animals in research.

\subsection{Blood test for diabetes mellitus}

Rats were fasted for 12 hours, after which blood was drawn from a tail vein at AM 9:00 without anesthesia, and plasma glucose (Glu), triglycerides (TG), total cholesterol (Cho), insulin and HbA1c levels were measured. The Glu and TG levels were determined using an Accutrend GCT (Roche Diagnostics, Mannheim, Germany). Cho levels were measured by the cholesterol oxidase method and the phosphotungstate-magnesium salt method using a Cholesterol E-Test Kit(Wako, Osaka, Japan). Insulin levels were measured using an ELISA Insulin Kit according to the manufacturer's instructions (Morinaga Institute of Biological Science Inc., Kanagawa, Japan). Briefly, monoclonal antibodies specific for rat insulin were pre-coated onto microplates, standards and samples were pipetted into the wells, and the microplates were incubated at $4^{\circ} \mathrm{C}$ for $2 \mathrm{~h}$. After washing to remove unbound materials, rat insulin antibodies were added to the wells at room temperature for 30 min. After washing, the substrates were added. The enzyme reactions yielded blue products that turned yellow when the stop solutions were added. The absorbance was measured with a microplate reader(BIO-RAD, California, USA) at $450 \mathrm{~nm}$. HbA1c levels were determined using an HLC-723GHbV (Tosoh Corp., Tokyo, Japan), which is a fully automated HPLC analyzer that uses a non-porous cation-exchange polymer that can separate the stable and labile Schiff fractions of $\mathrm{HbAlc}$, and shows no interference by carbamylated hemoglobin. Blood samples were collected into EDTA-containing tubes from a tail vein. The eluted hemoglobin fractions are monitored at $415 \mathrm{~nm}$ as well as at $500 \mathrm{~nm}$ as a reference wavelength, and the analysis time was 2.2 min per sample. All analyses were performed according to the manufacturer's instructions.

\subsection{RNA preparation}

Total RNAs were extracted from the retinas of 60 -weekold LETO and OLETF rats by the acid guanidium thiocyanate-phenol-chloroform extraction method ${ }^{32)}$ using Trizol reagent (Life Technologies Inc., Rockville, USA). The purity and concentrations of RNA were determined spectrophotometrically. The $\mathrm{OD}_{260} / \mathrm{OD}_{280}$ values of all RNAs used were greater than 1.8 , which indicates low protein contamination and high RNA purity. 


\subsection{Quantitative real-time reverse transcriptase-poly- merase chain reaction (RT-PCR)}

The RT reaction was performed using an RNA PCR Kit (AMV Ver 3.0, Takara Bio Inc., Shiga, Japan). One microgram of total RNA was mixed with $3 \mu \mathrm{l}$ of $10 \mathrm{mM}$ Tris-HCl buffer ( $\mathrm{pH} 8.3$ ) containing $5 \mathrm{mM} \mathrm{MgCl}_{2}$ and $50 \mathrm{mM} \mathrm{KCl}$. The following components were then added to give a final volume of $10 \mu \mathrm{l}$ : 1 unit/ $\mu \mathrm{l}$ RNase inhibitor, $10 \mathrm{mM}$ deoxynucleotide triphosphate, 2.5 units/ $\mu$ l reverse transcriptase, and $0.125 \mu \mathrm{M}$ oligo dT-adaptor primer. The $\mathrm{RT}$ reaction was performed at $42^{\circ} \mathrm{C}$ for $15 \mathrm{~min}$, followed by $5 \mathrm{~min}$ at $95^{\circ} \mathrm{C}$. The PCR reactions were performed using LightCycler FastStart DNA Master SYBR Green I according to the manufacturer's instructions (Roche Diagnostics Applied Science, Mannheim, Germany). Briefly, $2 \mu \mathrm{l}$ of cDNA was mixed with $2 \mu$ of reaction mixture, LightCycler FastStart DNA Master SYBR Green I Reaction Mix, containing FastStart Taq DNA Polymerase, reaction buffer, $\mathrm{MgCl}_{2}$, SYBR Green I dye, and deoxynucleotide triphosphate mix. The following components were then added to give a final volume of $20 \mu \mathrm{l}: 10 \mathrm{pmol}$ specific primers for IL-18, IL-18R $\alpha$, IL-18R $\beta$, IL-18 binding protein (IL-18BP), caspase-1 or glyceraldehyde-3-phosophate dehydrogenase (GAPDH). The primers used are summarized in Table 1. The PCR conditions were $95^{\circ} \mathrm{C}$ for 10 min, 50 cycles of $95^{\circ} \mathrm{C}$ for $10 \mathrm{~s}$ (denaturing), 53 (IL-18, IL-18BP), 55 (IL-18R $\beta), 57$ (IL-18R $\alpha$, caspase-1) or $60(\mathrm{GAPDH}){ }^{\circ} \mathrm{C}$ for $10 \mathrm{~s}$ (annealing), and $72^{\circ} \mathrm{C}$ for $5 \mathrm{~s}$ (extension). The quantities of PCR products were measured fluorometrically in a real-time manner using a LightCycler DX 400 (Roche Diagnostics Applied Science, Mannheim, Germany). After the completion of the $\mathrm{PCR}$ reactions, dissociation curves of the PCR products were generated using the LightCycler Software Version 4.0 program to detect nonspecific amplifica- tion, including primer-dimers, and to ascertain the quality of the amplification data. The differences in the threshold cycles for GAPDH and other groups (IL-18, IL-18R $\alpha$, IL-18R $\beta$, IL-18BP and caspase-1) were used to calculate the levels of mRNA expression in LETO and OLETF rats ${ }^{33)}$.

\subsection{Western blot analysis}

The retinas of 60-week-old LETO and OLETF rats were homogenized in saline on ice, and centrifuged at 1,500 rpm for $10 \mathrm{~min}$ at $4{ }^{\circ} \mathrm{C}$. The resultant supernatants were suspended in a buffer comprising $1.25 \mathrm{mmol} / \mathrm{l}$ Tris-HCl, $\mathrm{pH} 6.8$, $0.4 \%$ sodium dodecyl sulfate (SDS), $0.2 \%$ glycerol, $0.1 \%$ 2 -mercaptoethanol and $0.004 \%$ bromophenol blue, and boiled for $3 \mathrm{~min}$. A sample of total protein $(10 \mu \mathrm{g})$ was separated in a $15 \%$ polyacrylamide SDS gel, and the proteins were then transferred to polyvinylidene difluoride membranes (BIO-RAD, California, USA) using a semi-dry transfer cell(Trans-Blot SD Semi-Dry Electrophoretic Transfer Cell, BIO-RAD, California, USA). The transfer buffer used in the system contained $25 \mathrm{mmol} / \mathrm{l}$ Tris-HCl, $191 \mathrm{mmol} / \mathrm{l}$ glycine, 20\% methanol, and $0.0375 \%$ SDS. After transfer, nonspecific sites on the membranes were blocked with $5 \%$ non-fat dry milk in Tris-buffer $(20 \mathrm{mmol} / \mathrm{l}$ Tris-HCl, and 500 $\mathrm{mmol} / \mathrm{l} \mathrm{NaCl}, \mathrm{pH} 7.5$ ). The blots were probed with $0.31 \mathrm{mg} /$ 1 goat anti-rat IL-18 polyclonal antibody (Promega, Wisconsin, USA) or with $0.17 \mathrm{mg} / \mathrm{l}$ rabbit anti-rat GAPDH polyclonal antibody (IMGENEX, California, USA) for $2 \mathrm{~h}$ at room temperature. After washing with Tris-buffer containing $0.05 \%$ Tween 20 , the membranes were incubated with secondary alkaline-phosphatase conjugated anti-goat IgG (1:7000 dilution, Promega, Wisconsin, USA) or alkalinephosphatase conjugated anti-rabbit IgG (1:7000 dilution, Promega, Wisconsin, USA) for $2 \mathrm{~h}$ at room temperature, washed with Tris-buffer containing $0.1 \%$ Tween 20 , and in-

Table 1 Sequences of Primers used for Quantitative RT-PCR Analysis.

\begin{tabular}{cccc}
\hline Primer & & \multicolumn{1}{c}{ Sequence (5’ -3’ $)$} & $\begin{array}{c}\text { GenBank } \\
\text { Accession No. }\end{array}$ \\
\hline IL-18 & FOR & CGCAGTAATACGGAGCATAAATGAC & NM_019165 \\
& REV & GGTAGACATCCTTCCATCCTTCAC & \\
IL-18R $\alpha$ & FOR & AGCAGAAAGAGACGAGACACTAAC & XM_237088 \\
& REV & CTCCACCAGGCACCACATC & \\
IL-18R $\beta$ & FOR & GACCACAGGATTTAACATTCAGC & AJ550893 \\
& REV & AGCAGGACCTAGTGTTGATGATG & \\
IL-18BP & FOR & TTGGTGGGTCCTGCTTCTATATG & AF154569 \\
& REV & GGTCAGCGTTCCATTCAGTG & \\
Caspase-1 & FOR & TGAAGATGATGGCATTAAGAAGGC & NM_012762 \\
& REV & CAAGTCACAAGACCAGGCATATTC & \\
GAPDH & FOR & ACGGCACAGTCAAGGCTGAGA & NM_017008 \\
& REV & CGCTCCTGGAAGATGGTGAT & \\
\hline
\end{tabular}


cubated with a stabilized substrate for alkaline phosphatase (Promega, Wisconsin, USA ${ }^{33)}$.

\subsection{Protein measurement}

Protein levels in the retinas of LETO and OLETF rats at 10 and 60 weeks of age were determined according to the method of Bradford ${ }^{34)}$ using a Bio-Rad Protein Assay Kit (BIO-RAD, California, USA) with bovine serum albumin as the standard.

\subsection{Assay of IL-18 levels in LETO and OLETF rat retinas}

Retinas from LETO and OLETF rats at 10 and 60 weeks of age were homogenized in ultrapure water. The retinal homogenates were centrifuged at $1500 \mathrm{rpm}$ for $10 \mathrm{~min}$ at $4^{\circ} \mathrm{C}$, and the supernatants were used for the measurement of IL-18 levels using an Endogen ${ }^{\circledR}$ Rat IL-18 ELISA Kit according to the manufacturer's instructions (Invitrogen Cor., Camarillo, CA). Briefly, monoclonal antibodies specific for rat IL-18 were pre-coated onto microplates. Standards and samples were pipetted into the wells, and the microplates were incubated at room temperature for $2 \mathrm{~h}$. After washing to remove unbound materials, biotinylated antibodies were added to the wells. After washing, streptavidin-HRP solutions were added, and the wells were washed to remove unbound materials after which the substrates were added. The enzyme reactions yielded blue products that turned yellow when the stop solutions were added. The absorbance was measured with a microplate reader (BIO-RAD, California, USA) at $450 \mathrm{~nm}^{33)}$. The detection area of IL-18 was $15.6-1000 \mathrm{pg} / \mathrm{ml}$, and the IL-18 levels in this study were within detection area.

\subsection{Assay of IFN- $\gamma$ levels in LETO and OLETF rat retinas}

Retinas from LETO and OLETF rats at 10 and 60 weeks of age were homogenized in ultrapure water. The retinal homogenates were centrifuged at $1500 \mathrm{rpm}$ for $10 \mathrm{~min}$ at $4^{\circ} \mathrm{C}$, and the supernatants were used for the measurement of IFN- $\gamma$ levels using an Endogen ${ }^{\circledR}$ Rat IFN $\gamma$ ELISA Kit according to the manufacturer's instructions (Pierce Biotechnology Inc., Wisconsin, USA). Briefly, monoclonal antibodies specific for rat IFN- $\gamma$ were pre-coated onto microplates. Standards and samples were pipetted into the wells, and the microplates were incubated at room temperature for 1 h. After washing to remove unbound materials, biotinylated antibodies were added to the wells. After washing, streptavidin-HRP solutions were added, and the wells were washed to remove unbound materials after which the substrates were added. The enzyme reactions yielded blue products that turned yellow when the stop solutions were added. The absorbance was measured with a microplate reader (BIO-RAD, California, USA) at $450 \mathrm{~nm}^{33)}$. The detection area of IFN- $\gamma$ was 8-500 pg/ml, and The IFN- $\gamma$ levels in this study were within detection area.

\subsection{Statistical analysis}

All values are represented as mean \pm standard error of the mean (S.E.). Unpaired Student's or Aspin-Welch's $t$-tests were used for statistical analysis, and multiple groups were evaluated by one-way analysis of variance (ANOVA) followed by Dunnett's multiple comparison. $P$ values less than 0.05 were considered significant. The number of experiments performed is given in the Table and Figure legends.

\section{RESULTS}

\subsection{Changes in food intake, water consumption, body weight and blood markers for diabetes mellitus in LETO and OLETF rats}

Table 2 shows the changes in food intake, water consumption, body weight and blood markers for diabetes of LETO and OLETF rats at 10, 38 and 60 weeks of age. The food and water intakes of OLETF rats were higher than those of LETO rats. The body weights of the 38-week-old OLETF rats were 1.27-fold those of LETO rats at the same age. In addition, the Glu, TG, Cho and insulin levels of the OLETF rats were significantly higher than those of the LETO rats. In 60-week-old OLETF rats, the Glu, TG and Cho levels were also significantly higher than those of the same age LETO rats. On the other hand, the body weight and plasma insulin levels were lower, and HbA1c levels were significantly higher than in 60-week-old LETO rats.

\subsection{Expression of IL-18 mRNA and protein in the retinas of LETO and OLETF rats}

Figure 1 shows the expression levels of the mRNAs for IL-18, IL-18R $\alpha$, IL-18R $\beta$, IL-18BP and caspase-1 in the retinas of LETO and OLETF rats aged 60 weeks as determined by the quantitative real-time PCR method. In the retinas of OLETF rats, high expression levels of the mRNAs for IL-18, IL-18R $\alpha$, IL-18 $\beta$, IL-18BP and caspase-1 were observed in comparison with those in LETO rats. Furthermore, the mRNA expression levels of IL-18 and caspase-1 in the retinas of OLETF rats were significantly higher than those in LETO rats. Figure 2 shows the expression of mature IL-18 in 60-week-old OLETF rat retinas as determined by western blot. Although no expression of mature IL-18 (18-kDa) was observed in the retinas of 60-week-old LETO rats, OLETF rats of the same age showed clear expression of mature IL-18. On the other hand, in the rat which was perfused by cold saline, the significantly different of IL-18 mRNA was not observed between LETO and OLETF rats aged 60 weeks (LETO; $8.0 \pm 1.1$, OLETF; $9.7 \pm$ $1.5, \times 10^{-5}$, means \pm S.E. of 3 experiments), and the expression of mature IL-18 protein was not detected by western blot. 
Table 2 Body Weight and Some Blood Test Values for Diabetes Mellitus in 10-, 38- and 60-Week-Old LETO and OLETF Rats.

\begin{tabular}{|c|c|c|c|c|c|c|}
\hline & \multicolumn{2}{|c|}{ 10-week-old } & \multicolumn{2}{|c|}{ 38-week-old } & \multicolumn{2}{|c|}{60 -week-old } \\
\hline & LETO & OLETF & LETO & OLETF & LETO & OLETF \\
\hline Food intake (g/day/rat) & $22.3 \pm 3.1$ & $26.1 \pm 1.3^{*}$ & $26.9 \pm 2.2$ & $38.5 \pm 1.6^{*}$ & $29.7 \pm 1.9$ & $38.9 \pm 3.2 *$ \\
\hline Water consumed (ml/day/rat) & $30.2 \pm 1.2$ & $28.8 \pm 0.9$ & $38.6 \pm 2.8$ & $82.3 \pm 2.9^{*}$ & $39.4 \pm 2.6$ & $79.8 \pm 3.6^{*}$ \\
\hline Body weight (g) & $220.6 \pm 8.1$ & $278.3 \pm 6.7^{*}$ & $488.6 \pm 14.2$ & $621.3 \pm 19.7 *$ & $466.9 \pm 13.9$ & $408.3 \pm 14.9^{*}$ \\
\hline Glu (mg/dl) & $103.8 \pm 2.9$ & $124.3 \pm 5.3^{*}$ & $119.3 \pm 4.9$ & $213.5 \pm 15.7^{*}$ & $127.3 \pm 3.2$ & $238.1 \pm 18.3^{*}$ \\
\hline $\mathrm{TG}(\mathrm{mg} / \mathrm{dl})$ & $101.6 \pm 7.6$ & $114.5 \pm 10.1$ & $128.0 \pm 9.3$ & $419.8 \pm 22.2 *$ & $119.8 \pm 7.6$ & $335.0 \pm 8.1^{*}$ \\
\hline Cho (mg/dl) & $84.7 \pm 21.7$ & $106.3 \pm 9.6$ & $101.4 \pm 11.4$ & $209.2 \pm 11.1^{*}$ & $93.8 \pm 21.2$ & $253.3 \pm 20.3^{*}$ \\
\hline Insulin (ng/dl) & $95.3 \pm 9.5$ & $99.5 \pm 3.0$ & $105.5 \pm 11.6$ & $237.4 \pm 26.6^{*}$ & $103.7 \pm 7.9$ & $68.7 \pm 11.0 *$ \\
\hline HbAlc (\%) & - & - & - & - & $2.9 \pm 0.07$ & $4.5 \pm 0.23^{*}$ \\
\hline
\end{tabular}

The Glu and TG levels were determined using an Accutrend GCT; Cho levels were measured using a Cholesterol E-Test Kit. Insulin was determined using the ELISA method, and HbA1c was analyzed by HLC-723GHbV. The data are presented as means \pm S.E. of 8 independent rats. ${ }^{* 1} p<0.05$ vs. 10 -week-old LETO rats for each category. ${ }^{* 2} p<0.05$ vs. 38 -week-old LETO rats for each category. ${ }^{* 3}$ $p<0.05$ vs. 60 -week-old LETO rats for each category
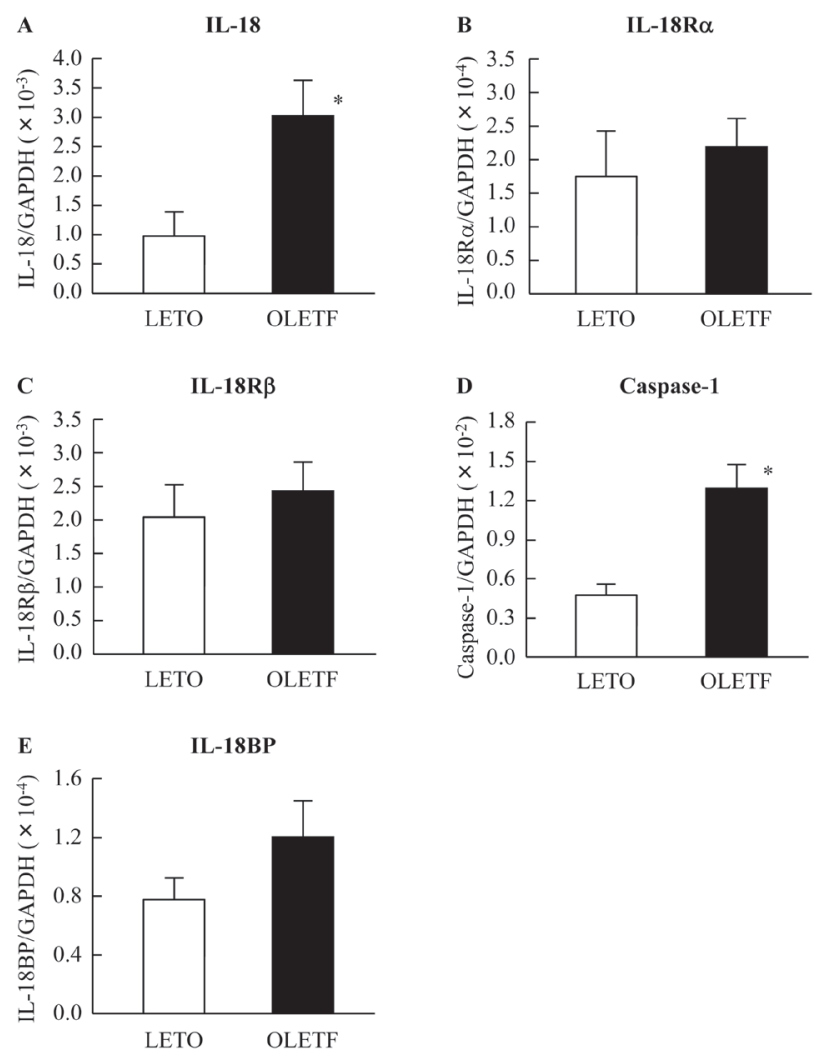

Fig. 1 Expression of IL-18-Related Genes in the Retinas of 60-week-old LETO and OLETF Rats. mRNA expression levels were determined by the quantitative real-time RT-PCR method. A, IL-18; B, IL-18R $\alpha$; C, IL-18R $\beta$; D, IL-18BP; E, caspase-1. Open columns, LETO rats; closed columns, OLETF rats. The data are presented as means \pm S.E. of 4 independent rats. ${ }^{*} p<0.05$ vs. LETO rats.

\section{LETO OLETF}

GAPDH

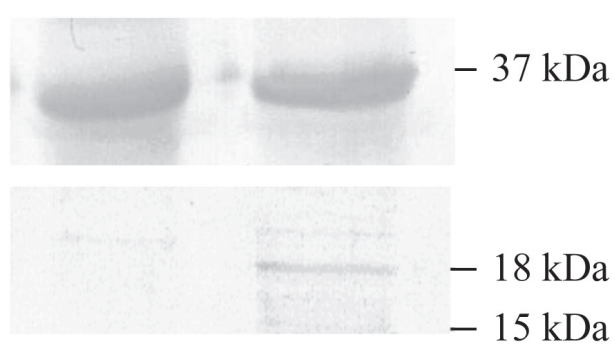

Fig. 2 Expression of the Mature IL-18 Protein in the Retinas of 60-week-old LETO and OLETF Rats. The mature IL-18 protein was detected byWestern blot analysis.

\subsection{Levels of IL-18 and IFN- $\gamma$ production in the retinas of LETO and OLETF rats}

Figure 3 shows the levels of IL-18 and IFN- $\gamma$ in the retinas of LETO and OLETF rats aged 10 and 60 weeks as determined by ELISA. The levels of IL-18 and IFN- $\gamma$ in the retinas of 10-week-old rats did not differ between LETO and OLETF rats, and both IL-18 and IFN- $\gamma$ levels in the retinas of 60 -week-old OLETF rats were significantly greater than in the retinas of 60 -week-old LETO rats. The IFN- $\gamma$ levels increased with increasing IL-18 levels in the retinas of 60 -week-old OLETF rats (Fig. 4). Table 3 shows the correlation coefficients $(r)$ between the IL-18 levels and blood test values for diabetes mellitus (Glu, TG, Cho, insulin and $\mathrm{HbA1c}$ ) in 60-week-old OLETF rats. Body weight, Cho, TG, Cho and insulin levels showed no significantly relationship to IL-18 and IFN- $\gamma$ levels. Although, the IL-18 and IFN- $\gamma$ levels in retinas of 60 -week-old OLETF rats increased with an increase in Glu level, the change was not statistically significant. Both of the IL-18 and IFN- $\gamma$ levels of 60-week-old OLETF rats increased with the in- 

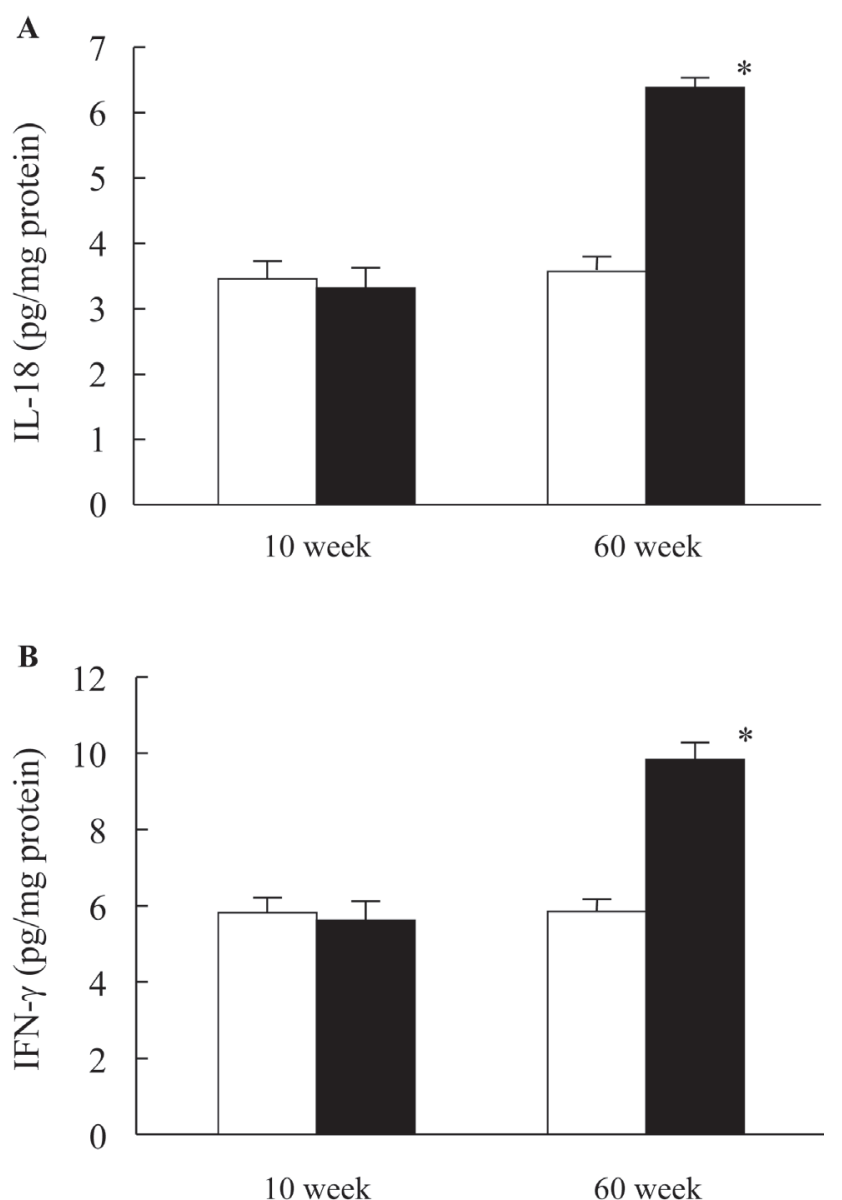

Fig. 3 IL-18 (A) and IFN- $\gamma$ (B) Levels in the Retinas of 10- and 60-week-old LETO and OLETF Rats. IL-18 and IFN- $\gamma$ levels were determined using the ELISA method. Open columns, LETO rat retinas; closed columns, OLETF rat retinas. The data are presented as means \pm S.E. of 8 independent rat retinas. $* p<0.05$, vs. LETO rats.

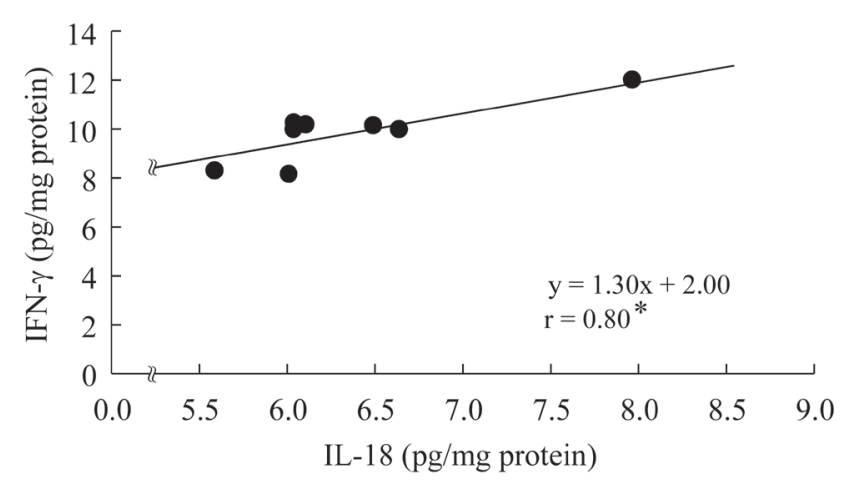

Fig. 4 Relationship between of the Levels of IL-18 and IFN- $\gamma$ in the Retinas of 60 -week-old OLETF Rats. $* p<0.05$.
Table 3 Correlation Coefficients $(r)$ among IL-18 and IFN- $\gamma$ Levels and Body Weight, Glu, TG, Cho, Insulin and HbA1c Levels in 60-Week-Old OLETF Rats.

\begin{tabular}{llc}
\hline \multicolumn{1}{c}{ Relationship } & IL-18 & IFN- $\gamma$ \\
\hline vs. body weight & 0.10 & 0.24 \\
vs. Glu & 0.67 & 0.49 \\
vs. TG & 0.35 & 0.50 \\
vs. Cho & 0.02 & -0.18 \\
vs. insulin & 0.40 & 0.54 \\
vs. HbA1c & $0.75^{*}$ & $0.77^{*}$
\end{tabular}

The Glu and TG levels were determined using an Accutrend GCT; Cho levels were measured by Cholesterol E-Test Kit. Insulin, IL-18 and IFN- $\gamma$ levels were determined using the ELISA method, and $\mathrm{HbAlc}$ was analyzed by HLC-723GHbV. The data represent mean values for 8 independent rats. ${ }^{*} p<0.05$.

crease in HbA1c, and this relationship was significant (Table 3). Table 4 shows the effect of acute hyperglycemia on IL-18 and IFN- $\gamma$ production in 60-week-old OLETF rats 60 min after the oral administration of a glucose solution $(3.0 \mathrm{~g} / \mathrm{kg})$. The rapid rise in Glu following the oral administration of glucose did not affect the IL-18 and IFN- $\gamma$ levels in the retinas of LETO rats. Whereas, the IL-18 and IFN- $\gamma$ levels in the retinas of OLETF rats rose significantly following the oral administration of glucose (Table 4). On the other hand, at 60 min after the oral administration of glucose, the enhancement of IL-18 mRNA level was observed in the retina of 60 -week-old OLETF rats perfused by cold saline (without glucose; $9.4 \pm 1.8$, with glucose; 13.5 $\pm 1.7, \times 10^{-5}$, means \pm S.E. of 3 experiments), and IL-18 levels in the retina of 60-week-old OLETF rats with oral administration of glucose was also higher than that without oral administration of glucose (without glucose; $0.9 \pm 0.2$, with glucose; $1.5 \pm 0.3, \mathrm{pg} / \mathrm{mg}$ protein, means \pm S.E. of 3 experiments), however, the expression of IL-18 mRNA and IL-18 levels were a little in comparison with blood in the retina of 60-week-old OLETF rats.

\section{DISCUSSION}

IL-18, which induces IFN- $\gamma$ production, is a well-known pleiotropic cytokine that regulates innate and acquired immune responses, and plays an important role in inflammatory action ${ }^{22,23)}$. In this study, we determined the expression of IL-18 in diabetic retinas using OLETF rats, a model of type 2 diabetes mellitus. In addition, we investigated whether hyperglycemia relates to the expression of 
Changes of Interleukin 18 in OLETF Rat Retina

Table 4 Changes in IL-18 and IFN- $\gamma$ Levels in 60-Week-Old LETO and OLETF Rats in Response to an Oral Glucose Tolerance Test.

\begin{tabular}{lccrccc}
\hline & \multicolumn{2}{c}{ LETO } & & \multicolumn{2}{c}{ OLETF } \\
\cline { 2 - 3 } \cline { 5 - 6 } & Purified water & Glucose & & Purified water & Glucose \\
\hline Glu $(\mathrm{mg} / \mathrm{dl})$ & $125.3 \pm 7.9$ & $228.9 \pm 16.7^{* 1}$ & & $225.5 \pm 30.1$ & $482.6 \pm 33.1^{* 1,2}$ \\
IL-18 (pg/mg protein) & $3.5 \pm 0.8$ & $3.6 \pm 0.9$ & & $6.3 \pm 1.2$ & $9.9 \pm 1.6^{*_{1,2}}$ \\
IFN- $\gamma(\mathrm{pg} / \mathrm{mg}$ protein) & $5.8 \pm 0.7$ & $5.8 \pm 1.0$ & & $9.6 \pm 1.1$ & $15.1 \pm 2.7^{*_{1,2}}$ \\
\hline
\end{tabular}

The Glu, IL-18 and IFN- $\gamma$ levels in 60-week-LETO and OLETF rats were measured 60 min after the oral administration of glucose $(3.0 \mathrm{~g} / \mathrm{kg})$. Glu was determined using an Accutrend; IL-18 and IFN- $\gamma$ levels were measured by the ELISA method. The data are presented as means \pm S.E. of 3 independent rat retinas. ${ }^{* 1} p<0.05$ vs. purified water-administered LETO rats for each category. ${ }^{{ }^{*}} p<0.05$ vs. purified wateradministered OLETF rats for each category.

IL-18 and IFN- $\gamma$ in OLETF rat retinas.

In studies to identify changes in retinal levels of IL-18 in diabetes mellitus, the selection of the experimental animal is very important. Animal models used to investigate the ophthalmological secondary complications of diabetic mellitus include streptozotocin-induced diabetic rats as an animal model for insulin-dependent diabetes mellitus, and galactose fed rats as an animal model for sugar cataracts ${ }^{35-39)}$. Hyperglycemia is present in streptozotocin-induced diabetic rats, but not in galactose fed rats. However, the general pathophysiology of these models differs from that of non-insulin-dependent diabetes mellitus in humans. On the other hand, the general pathophysiology of GK (GotoKakizaki) rats, which are used as a model animal for type 2 diabetes mellitus, is similar to that of humans ${ }^{40)}$. However, GK rats develop type 2 diabetes mellitus without metabolic syndrome. The OLETF rat is known as a model animal for type 2 diabetes mellitus via a metabolic syndrome ${ }^{41)}$. Nearly $100 \%$ of male OLETF rats develop a diabetic syndrome by 25 weeks of age. The food intake and water consumption in OLETF rats are higher, and the body weight and TG levels of OLETF rats are significantly increased than that in LETO rat. This enhancement of TG levels causes insulin resistance. Thereby, hyperglycemia and hyperinsulinemia are exhibited in the early phases of the disease, which makes them a suitable model for human type 2 diabetes mellitus ${ }^{42-45)}$. With continued aging, the rats eventually develop hypoinsulinemia as a result of islet beta cell deterioration ${ }^{42,45)}$, and plasma insulin levels in OLETF rats over 60 weeks of age are lower than in LETO rats of the corresponding age used as normal controls ${ }^{46,47)}$. In addition, our previous studies have shown that a delay in corneal wound healing, lens opacification via IL-18 and IFN- $\gamma$ expression and retinal damage can be observed in 60 -week-old OLETF rats $^{48-50)}$, and Miyamuraet $a l{ }^{50)}$ have demonstrated the usefulness of OLETF rats as a model of diabetic retinal disease. The basement membranes of the retinal capillaries of 56-week-old OLETF rats are significantly thicker than in LETO rats, and the ratio of the peri- cyte area to the capillary cross-section area is significantly lower. The endothelial cell cytoplasm degenerates, and the vascular corrosion cast of a 56-week-old OLETF rat shows caliber irregularity, narrowing, tortuosity and loop formations of the capillaries. Furthermore, the electroretinograms (ERG)are similar to those seen in diabetic patients ${ }^{51,52)}$. From these reports, OLETF rats may provide a better model than streptozotocin-induced diabetic rats or GK rats for studies to clarify the significance of IL-18 in the retina of diabetes mellitus.

The body weights of 38-week-old OLETF rats were 1.27fold higher than those of 38-week-old LETO rats. Plasma Glu, TG and Cho levels in OLETF rats increased with age, and the plasma insulin levels in 38-week-old OLETF rats were also higher than those in 38-week-old LETO rats. These results indicate that the 38 -week-old OLETF rats had developed diabetes mellitus via insulin resistance. Consistent with the results in 38-week-old OLETF rats, the body weights and plasma insulin levels of 60-week-old OLETF rats were lower than those of 60-week-old LETO rats (Table 2). Hirashima et $a l^{46)}$ reported atrophy or the disappearance of beta cells in OLETF rats older than 60 weeks of age, and found that plasma insulin levels were lower than in LETO rats $^{47)}$. These findings suggest that the type 2 diabetes mellitus in 60-week-old OLETF rats has reached a fairly advanced stage, and that the changes may be due to the deterioration of islet beta cells with the progression of the disease. It is known that early symptoms of diabetic retinopathy are seen in 60-week-old OLETF rat ${ }^{51,52)}$, and the development of secondary ophthalmological complications of diabetes mellitus such as in the cornea and lens show that the retina is also effected by hyperglycemia $^{49,51-53)}$. Therefore, we confirmed the onset of cataracts, and used 60-week-old OLETF rats in which lens opacification can be observed in this study (some data are showed in Ref. ${ }^{49)}$. These results support the use of 60 -week-old OLETF rats as a model for the early phases in the development of diabetic retinopathy.

The IL-18 levels in the retinas of 10-week-old OLETF 
rats, which do not show signs of secondary ophthalmological complications of diabetes mellitus, were approximately $3.3 \mathrm{pg} / \mathrm{mg}$ protein, similar to the level in LETO rats (Fig. 3 ). On the other hand, higher expression levels of the mRNAs for IL-18, IL-18R $\alpha$, IL-18 $\beta$ and caspase-1 were observed in the retinas of 60-week-old OLETF rats that did display secondary ophthalmological complications of diabetes mellitus than in LETO rats, and the elevations were significant in the case of the IL-18 and caspase-1 mRNAs (Fig. 1). The expression of the mature IL-18 protein in the retinas of 60-week-old OLETF rats was also observed to be significantly higher than in LETO rats (Fig. 2 and $3 \mathrm{~A}$ ). The IFN- $\gamma$ level in the retinas of OLETF rats was also higher than in LETO rats, and a close relationship was observed between the levels of IL-18 and IFN- $\gamma$ (Fig. 3B and 4). In addition, the 60-week-old OLETF rats by dietary restriction did not develop the diabetic mellitus (Glu; $129.0 \pm 6.8 \mathrm{mg} / \mathrm{dl}$, insulin; $101.5 \pm 8.1 \mathrm{ng} / \mathrm{dl}$, means \pm S.E. of 3 experiments), and the IL-18 and IFN- $\gamma$ levels in retina of 60 -week-old OLETF rats without diabetic mellitus by dietary restriction (IL-18; $3.5 \pm 1.3$, IFN- $\gamma ; 5.7 \pm 1.4$, means \pm S.E. of 3 experiments) was similar to LETO rats at 60 weeks of age. Retinal inflammation is associated with $\mathrm{T}$ lymphocyte infiltration ${ }^{54)}$, and an increase in IFN- $\gamma$ is a classical part of the Th1 cytokine response. Geiger et al. reported that transgenic mice expressing IFN- $\gamma$ in the retina developed eye inflammation and photoreceptor $\operatorname{loss}^{55)}$. Furthermore, IFN- $\gamma$ has not been detected in the vitreous or aqueous fluid of patients with proliferative diabetic retinopathy ${ }^{15)}$. Therefore, it seems likely that the retina has a selective response to the diabetic insult. These results suggest that IFN- $\gamma$ production via IL-18 may cause inflammation in the retinas of 60-week-old OLETF rats. On the other hand, the expression of the mRNA for IL-18BP, a protein that inhibits the activation of IL-18, in the retinas of OLETF rats also tended to be higher than in LETO rats (Fig. 1). Soluble IL-18BP, which has recently been purified and cloned from serum and urine, shows no homology to IL-18R, but is a specific, functional inhibitor of IL-18 that may act as an endogenous inhibitor of circulating IL-18 ${ }^{56,57)}$. Hurgin et al. ${ }^{58)}$ reported that an elevation in IL-18BP expression is induced by IFN- $\gamma$. Therefore, the elevation in the expression of IL-18BP mRNA in the retinas of OLETF rats may be caused by the production of IFN- $\gamma$ through the activation of IL-18.

It is very important to elucidate the precise process by which IL-18 enhancement occurs in the retinas of OLETF rats. At present, we have demonstrated changes in IL-18 and IFN- $\gamma$ levels in 60-week-LETO and OLETF rats $60 \mathrm{~min}$ after the oral administration of glucose $(3.0 \mathrm{~g} / \mathrm{kg}$, Table 4$)$. The Glu levels in LETO rats administered the glucose solution were similar to those in OLETF rats administered purified water. However, the IL-18 and IFN- $\gamma$ levels in LETO rats did not increase following the administration of glucose solution, and the IL-18 and IFN- $\gamma$ levels in LETO rats administered glucose solution were lower than those in OLETF rats administered purified water. Consistent with the results in LETO rats, the IL-18 and IFN- $\gamma$ levels in the retina of OLETF rats were increased by the oral administration of glucose (Table 4), and the relationships $(r)$ between the Glu and IL-18 or IFN- $\gamma$ levels in the retina of OLETF rats administered glucose solution(vs. IL-18, 0.77; IFN- $\gamma$ vs., 0.78$)$ were higher than in OLETF rats administered purified water (vs. IL-18, 0.65 ; IFN- $\gamma$ vs., 0.59 ). These results suggest that chronic hyperglycemia may enhance the immune activation, as reflected in the increased IL-18 and IFN- $\gamma$ levels, in diabetes mellitus. In addition, we measured HbA1c levels, and demonstrated relationships between it and the IL-18 and IFN- $\gamma$ levels. It is known that retinal HbA1c levels in rats are lower than in humans with type 2 diabetes mellitus, and Taniguchi et al. ${ }^{59)}$ have shown that HbA1c levels in 25-week-old LETO and OLETF rats are approximately $2.9 \%$ and $3.5 \%$, respectively. In this study, the HbA1c levels in 60-week LETO and OLETF rats were similar to those reported by Taniguchi et al.,59) and were higher in OLETF rats than in LETO rats. The relationships between the levels of IL-18 or IFN- $\gamma$ and HbA1c are close, and are closer than the relationships between the levels of IL-18 or IFN- $\gamma$ and Glu (Table 3). Therefore, it is hypothesized that long-term hyperglycemia induces an enhancement in the expression of genes that lead to IL-18 production(IL-18, IL-18R and caspase-1), so that IFN- $\gamma$ levels via IL-18 increase in retinas.

The IL-18 levels in serum of 60-week-old OLETF rats were also significantly higher than 10-week-old OLETF rats (10 weeks of age; $3.3 \pm 1.3,60$ weeks of age; $8.9 \pm 1.7$, pg/ $\mathrm{mg}$ protein, means \pm S.E. of 3 experiments). Whereas, the different of IL-18 mRNA was not observed between LETO and OLETF rats aged 60 weeks perfused by cold saline, and the expression of mature IL-18 protein was not detected in the retina of 60-week-old OLETF rat perfused by cold saline. These results show that the inflammatory cells in the blood relate the enhancement of IL-18 in the retina. On the other hand, the IL-18 levels in the retinas of 60-weekold OLETF rats rose significantly following the oral administration of $3.0 \mathrm{~g} / \mathrm{kg}$ glucose (Table 4); however, the rapid rise in Glu at 60 min after the oral administration of glucose did not affect the IL-18 levels in the serum of 60 -week old OLETF rats (without glucose; $8.6 \pm 1.3$, with glucose; $8.9 \pm$ $1.6, \mathrm{pg} / \mathrm{mg}$ protein, means \pm S.E. of 3 experiments). Moreover, the IFN- $\gamma$ is not detected by used kit in the serum of 10- and 60-week-old OLETF rats. In addition, at $60 \mathrm{~min}$ after the oral administration of glucose, the expression of IL-18 mRNA and IL-18 levels in the retina without blood were a little than blood in the retina of 60-week-old OLETF rats. These results suggest that the cells in the blood locally caused the IL-18 and IFN- $\gamma$ in the retina under the rapid enhancement of Glu. It was known that the retina of OLETF rats was injured, and the inflammatory cells gather 
in the injured $\operatorname{area}^{51,52)}$. Taken together, it was possible that the inflammatory cells were gather in the blood of retina, and rapidly enhanced Glu may accelerate the release of IL-18 from the inflammatory cells in retinal blood vessel, resulting in enhancement of IL-18 in retina of the OLETF rats in this study.

Further studies are needed to elucidate the release and distribution of IL-18 in the retina of OLETF rats using histochemical procedure. In addition, it is important to clarify whether treatment with antihyperglycemic drugs can prevent retinopathy in diabetic patients. Therefore, we next plan to investigate the distribution of IL-18 in the retina of OLETF rats using histochemical procedure, and demonstrate the effects of orally administered antihyperglycemic drugs on IL-18 and IFN- $\gamma$ production in the retinas of OLETF rats with diabetes mellitus.

\section{CONCLUSION}

The present study, we demonstrate the enhancement of IL-18 expression in the retinas of OLETF rats, a spontaneous diabetic animal model with metabolic syndrome. The expression levels of IL-18 mRNA and protein in the retinas of 60-week-old OLETF rats are higher than in LETO rats of the corresponding age, and the inflammatory cells in the blood relate the enhancement of IL-18 in the retina. In addition, we report the relationship between hyperglycemia and IL-18 production in the retinas of OLETF rats. A close relationship was observed among the levels of IL-18, IFN- $\gamma$ and $\mathrm{HbAlc}$, and chronic hyperglycemia may accelerate the release of IL-18 and IFN- $\gamma$ from inflammatory cells in retinal blood vessel. It is possible that IFN- $\gamma$ production via IL-18 in the retinas of 60-week-old OLETF rats is caused by hyperglycemia, and this may play a role in the inflammation observed in OLETF rat retinas.

\section{References}

1) King, H.; Aubert, R. E.; Herman, W. H. Global burden of diabetes, 1995-2025: prevalence, numerical estimates, and projections. Diabetes Care 21, 1414-1431 (1998).

2) Yoon, K. H.; Lee, J. H.; Kim, J. W.; Cho, J. H.; Choi, Y. H.; Ko, S. H.; Zimmet, P.; Son, H. Y. Epidemic obesity and type 2 diabetes in Asia. Lancet 368, 1681-1688 (2006).

3) Schrauwen, P.; Hesselink, M. K. Reduced tricarboxylic acid cycle flux in type 2 diabetes mellitus? Diabetologia 51, 1694-1697 (2008).

4) Abu, El-Asrar, A. M.; Desmet, S.; Meersschaert, A.; Dralands, L.; Missotten, L.; Geboes, K. Expression of the inducible isoform of nitric oxide synthase in the retinas of human subjects with diabetes mellitus. Am.
J. Ophthalmol.132, 551-556(2001).

5) Elner, S. G.; Elner, V. M.; Jaffe, G. J.; Stuart, A.; Kunkel, S. L.; Strieter, R. M. Cytokines in proliferative diabetic retinopathy and proliferative vitreoretinopathy. Curr. Eye Res. 14, 1045-1053 (1995).

6) Aiello, L. P.; Avery, R. L.; Arrigg, P. G.; Keyt, B. A.; Jampel, H. D.; Shah, S. T.; Pasquale, L. R.; Thieme, H.; Iwamoto, M. A.; Park, J. E.; Nguyen, H. V.; Aiello, L. M.; Ferrara, N.; King, G. L. Vascular endothelial growth factor in ocular fluid of patients with diabetic retinopathy and other retinal disorders. N. Engl. J. Med. 331, 1480-1487 (1994).

7) Krady, J. K.; Basu, A.; Allen, C. M.; Xu, Y.; LaNoue, K. F.; Gardner, T. W.; Levison, S. W. Minocycline reduces proinflammatory cytokine expression, microglial activation, and caspase-3 activation in a rodent model of diabetic retinopathy. Diabetes 54, 1559-1565 (2005).

8) Kern, T. S. Contributions of inflammatory processes to the development of the early stages of diabetic retinopathy. Exp. Diabetes Res. 2007, 95103 (2007).

9) Schroder, S.; Palinski, W.; Schmid-Schonbein, G. W. Activated monocytes and granulocytes, capillary nonperfusion, and neovascularization in diabetic retinopathy. Am. J. Pathol. 139, 81-100 (1991).

10) Miyamoto, K.; Khosrof, S.; Bursell, S. E.; Rohan, R.; Murata, T.; Clermont, A. C.; Aiello, L. P.; Ogura, Y.; Adamis, A. P. Prevention of leukostasis and vascular leakage in streptozotocin-induced diabetic retinopathy via intercellular adhesion molecule-1 inhibition. Proc. Natl. Acad. Sci. USA. 96, 10836-10841(1999).

11) Boeri, D.; Maiello, M.; Lorenzi, M. Increased prevalence of microthromboses in retinal capillaries of diabetic individuals. Diabetes 50, 1432-1439 (2001).

12) Joussen, A. M.; Poulaki, V.; Mitsiades, N.; Kirchhof, B.; Koizumi, K.; Döhmen, S.; Adamis, A. P. Nonsteroidal anti-inflammatory drugs prevent early diabetic retinopathy via TNF-alpha suppression. Faseb. J. 16, 438440 (2002).

13) Kowluru, R. A.; Odenbach, S. Role of interleukin-1beta in the pathogenesis of diabetic retinopathy. $\mathrm{Br}$. J. Ophthalmol. 88, 1343-1347(2004).

14) Vincent, J. A.; Mohr, S. Inhibition of caspase-1/interleukin-1beta signaling prevents degeneration of retinal capillaries in diabetes and galactosemia. Diabetes 56, 224-230 (2007).

15) Abu, el, Asrar, A. M.; Maimone, D.; Morse, P. H.; Gregory, S.; Reder, A. T. Cytokines in the vitreous of patients with proliferative diabetic retinopathy. Am. J. Ophthalmol. 114, 731-736 (1992).

16) Tang, S.; Scheiffarth, O. F.; Thurau, S. R.; Wildner, G. Cells of the immune system and their cytokines in epiretinal membranes and in the vitreous of patients with proliferative diabetic retinopathy. Ophthalmic Res. 25, 177-185(1993). 
17) Meleth, A. D.; Agron, E.; Chan, C. C.; Reed, G. F.; Arora, K.; Byrnes, G.; Csaky, K. G.; Ferris, F. L. 3rd; Chew, E. Y. Serum inflammatory markers in diabetic retinopathy. Invest. Ophthalmol. Vis. Sci. 46, 4295-4301 (2005).

18) Patel, J. I.; Tombran-Tink, J.; Hykin, P. G.; Gregor, Z. J.; Cree, I. A. Vitreous and aqueous concentrations of proangiogenic, antiangiogenic factors and other cytokines in diabetic retinopathy patients with macular edema: Implications for structural differences in macular profiles. Exp. Eye Res. 82, 798-806 (2006).

19) Maier, R.; Weger, M.; Haller-Schober, E. M.; El-Shabrawi, Y.; Wedrich, A.; Theisl, A.; Aigner, R.; Barth, A.; Haas, A. Multiplex bead analysis of vitreous and serum concentrations of inflammatory and proangiogenic factors in diabetic patients. Mol. Vis. 14, 637-643(2008).

20) Murugeswari, P.; Shukla, D.; Rajendran, A.; Kim, R.; Namperumalsamy, P.; Muthukkaruppan, V. Proinflammatory cytokines and angiogenic and anti-angiogenic factors in vitreous of patients with proliferative diabetic retinopathy and Eales' disease. Retina 28, 817824(2008).

21) Vijay, S. K.; Mishra, M.; Kumar, H.; Tripathi, K. Effect of pioglitazone and rosiglitazone on mediators of endothelial dysfunction, markers of angiogenesis and inflammatory cytokines in type-2 diabetes. Acta Diabetol. 46, 27-33 (2009).

22) Ghayur, T.; Banerjee, S.; Hugunin, M.; Butler, D.; Herzog, L.; Carter, A.; Quintal, L.; Sekut, L.; Talanian, R.; Paskind, M.; Wong, W.; Kamen, R.; Tracey, D.; Allen, H. Caspase-1 processes IFN-gamma some inducing factor and regulates LPS-induced IFN-gamma production. Nature 386, 619-623 (1997).

23) Gu, Y.; Kuida, K.; Tsutsui, H.; Ku, G.; Hsiao, K.; Fleming, M. A.; Hayashi, N.; Higashino, K.; Okamura, H.; Nakanishi, K.; Kurimoto, M.; Tanimoto, T.; Flavell, R. A.; Sato, V.; Harding, M. W.; Livingston, D. J.; Su, M. S. Activation of interferon-gamma inducing factor mediated by interleukin-1beta converting enzyme. Science 275, 206-209 (1997).

24) Moriwaki, Y.; Yamamoto, T.; Shibutani, Y.; Aoki, E.; Tsutsumi, Z.; Takahashi, S.; Okamura, H.; Koga, M.; Fukuchi, M.; Hada, T. Elevated levels of interleukin-18 and tumor necrosis factor-alpha in serum of patients with type 2 diabetes mellitus: relationship with diabetic nephropathy. Metabolism 52, 605-608(2003).

25) Escobar-Morreale, H. F.; Botella-Carretero, J. I.; Villuendas, G.; Sancho, J.; San, Millán, J. L. Serum interleukin-18 concentrations are increased in the plycystic ovary syndrome: relationship to insulin resistance and obesity. J. Clin. Endocrinol. Metab. 89, 806-811 (2004).

26) Netea, M. G.; Joosten, L. A.; Lewis, E.; Jensen, D. R.; Voshol, P. J.; Kullberg, B. J.; Tack, C. J.; van, Krieken,
H.; Kim, S. H.; Stalenhoef, A. F.; van, de, Loo, F. A.; Verschueren, I.; Pulawa, L.; Akira, S.; Eckel, R. H.; Dinarello, C. A.; van, den, Berg, W.; van, der, Meer, J. W. Deficiency of interleukin-18 in mice leads to hyperphagia, obesity and insulin resistance. Nat. Med. 12, 650-656 (2006).

27) Esposito, K.; Nappo, F.; Marfella, R.; Giugliano, G.; Giugliano, F.; Ciotola, M.; Quagliaro, L.; Ceriello, A.; Giugliano, D. Inflammatory cytokine concentrations are acutely increased by hyperglycemia in humans. Circulation 106, 2067-2072 (2002).

28) Yang, L. P.; Sun, H. L.; Wu, L. M.; Guo, X. J.; Dou, H. L.; Tso, M. O.; Zhao, L.; Li, S. M. Baicalein reduces inflammatory process in a rodent model of diabetic retinopathy. Invest. Ophthalmol. Vis. Sci. 50, 2319-2327 (2009).

29) Torigoe, K.; Ushio, S.; Okura, T.; Kobayashi, S.; Taniai, M.; Kunikata, T.; Murakami, T.; Sanou, O.; Kojima, H.; Fujii, M.; Ohta, T.; Ikeda,. M.; Ikegami, H.; Kurimoto, M. Purification and characterization of the human interleukin-18 receptor. J. Biol. Chem. 272, 25737-25742 (1997).

30) Kim, S. H.; Reznikov, L. L.; Stuyt, R. J.; Selzman, C. H.; Fantuzzi, G.; Hoshino, T.; Young, H. A.; Dinarello, C. A. Functional reconstitution and regulation of IL-18 activity by the IL-18R beta chain. J. Immunol. 166, 148154(2001).

31) Nakanishi, K.; Yoshimoto, T.; Tsutsui, H.; Okamura, H. Interleukin-18 regulates both Th1 and Th2 responses. Annu. Rev. Immunol. 19, 423-474(2001).

32) Chomczynski, P.; Sacchi, N. Single-step method of RNA isolation by acid guanidinium thiocyanate-phenol-chloroform extraction. Anal. Biochem. 162, 156159 (1987).

33) Nagai, N.; Fukuhata, T.; Ito, Y.; Usui, S.; Hirano, K. Involvement of interleukin 18 in indomethacin-induced lesions of the gastric mucosa in adjuvant-induced arthritis rat. Toxicology 255, 124-130 (2009).

34) Bradford, M. M. A rapid and sensitive method for the quantitation of microgram quantities of protein utilizing the principle of protein-dye binding. Anal. Biochem. 72, 248-254(1976).

35) Kinoshita, J. H. Cataracts in galactosemia. (The Jonas S. Friendenwald Memorial Lecture). Invest. Ophthalmol. Vis. Sci. 4, 786-799 (1965).

36) Kinoshita, J. H. Mechanisms initiating cataract formation. (Proctor Lecture). Invest. Ophthalmol. Vis. Sci. 13, 713-724 (1974).

37) Fukushi, S.; Merola, L. O.; Kinoshita, J. H. Altering the course of cataracts in diabetic rats. Invest. Ophthalmol. Vis. Sci. 19, 313-315(1980).

38) Kador, P. F.; Akagi, Y.; Kinoshita, J. H. The effect of aldose reductase and its inhibition on sugar cataract formation. Metabolism 35, 5-19(1986). 
39) Akagi, Y.; Tasaka, H.; Terubayashi, H.; Ikebe, H.; Mori, K. In: Sakamoto, N.; Kinoshita, J. H.; Kador, P. F.; Hotta, N. (Ed.), Morphological classification of the prevention of aldose reductase inhibitor on rat galactose cataract. Current Concepts of Aldose Reductase and its Inhibition. Elsevier, New York USA; 1990: 157-160.

40) Wakuta, M.; Morishige, N.; Chikama, T.; Seki, K.; Nagano, T.; Nishida, T. Delayed wound closure and phenotypic changes in corneal epithelium of the spontaneously diabetic Goto-Kakizaki rat. Invest. Ophthalmol. Vis. Sci. 48, 590-596(2007).

41) Kawano, K.; Hirashima, T.; Mori, S.; Saitoh, Y.; Kurosumi, M.; Natori, T. Spontaneous long-term hyperglycemic rat with diabetic complications. Otsuka LongEvans Tokushima Fatty(OLETF) strain. Diabetes 41, 1422-1428(1992).

42) Ishida, K.; Mizuno, A.; Min, Z.; Sano, T.; Shima, K.. Which is the primary etiologic event in Otsuka LongEvans Tokushima Fatty rats, a model of spontaneous non-insulin-dependent diabetes mellitus, insulin resistance, or impaired insulin secretion? Metabolism 44, 940-945 (1995).

43) Sato, T.; Asahi, Y.; Toide, K.; Nakayama, N. Insulin resistance in skeletal muscle of the male Otsuka LongEvans Tokushima Fatty rat, a new model of NIDDM. Diabetologia 38, 1033-1041 (1995).

44) Ito, A.; Uriu, K.; Inada, Y.; Qie, Y.L.; Takagi, I.; Ikeda, M.; Hashimoto, O.; Suzuka, K.; Eto, S.; Tanaka, Y.; Kaizu, $\mathrm{K}$. Inhibition of neuronal nitric oxide synthase ameliorates renal hyperfiltration in streptozotocin-induced diabetic rat. J. Lab. Clin. Med. 138, 177-185(2001).

45) Yabuki, A.; Tahara, T.; Taniguchi, K.; Matsumoto, M.; Suzuki, S. Neuronal nitric oxide synthase and cyclooxygenase-2 in diabetic nephropathy of type 2 diabetic OLETF rats. Exp. Anim. 55, 17-25 (2006).

46) Hirashima, T.; Man, Z. W.; Mori, S.; Kawano, K. OLETF rat. Diabetes Frontier 9, 477-480 (1998).

47) Minami, A.; Ishimura, N.; Sakamoto, S.; Takishita, E.; Mawatari, K.; Okada, K.; Nakaya, Y. Effect of eicosapentaenoic acid ethyl ester v. oleic acid-rich safflower oil on insulin resistance in type 2 diabetic model rats with hypertriacylglycerolaemia. Br. J. Nutr. 87, 157162 (2002).

48) Nagai, N.; Murao, T.; Ito Y.; Okamoto, N.; Sasaki, M. Enhancing effects of sericin on corneal wound healing in Otsuka Long-Evans Tokushima fatty rats as a model of human type 2 diabetes. Biol. Pharm. Bull. 32, 1594-1599 (2009).
49) Nagai, N.; Murao, T.; Ito, Y.; Okamoto, N.; Okamura, H. Involvement of interleukin 18 in lens opacification of Otsuka Long-Evans Tokushima Fatty rats, a model of human type 2 diabetes. Curr. Eye Res. 36, 497-506 (2011).

50) Miyamura, N.; Bhutto, I. A.; Amemiya, T. Retinal capillary changes in Otsuka Long-Evans Tokushima fatty rats (spontaneously diabetic strain). Electron-microscopic study. Ophthalmic Res. 31, 358-566 (1999).

51) Yonemura, D. An electrophysiological study on activities of neuronal and non-neuronal retinal elements in man with reference to its clinical application. Nippon Ganka Gakkai Zasshi. 81, 1632-1665(1977).

52) Yamada, A. Alteration of electroretinogram in spontaneously diabetic rats: Effect of caloric restriction. $J$. Juzen Med. Soc. 110, 418-442(2001).

53) Nagai, N.; Murao, T.; Okamoto, N.; Ito, Y. Kinetic analysis of the rate of corneal wound healing in Otsuka long-evans Tokushima Fatty rats, a model of type 2 diabetes mellitus. J. Oleo. Sci. 59, 441-449 (2010).

54) Caspi, R. R.; Sun, B.; Agarwal, R. K. T cell mechanisms in experimental autoimmune uveoretinitis: susceptibility is a function of the cytokine response profile. Eye 11, 209-212 (1997).

55) Geiger, K.; Howes, E.; Gallina, M.; Huang, X. J.; Travis, G. H.; Sarvetnick, N. Transgenic mice expressing IFNgamma in the retina develop inflammation of the eye and photoreceptor loss. Invest. Ophthalmol. Vis. Sci. 35, 2667-2681 (1994).

56) Aizawa, Y.; Akita, K.; Taniai, M.; Torigoe, K.; Mori, T.; Nishida, Y.; Ushio, S.; Nukada, Y.; Tanimoto, T.; Ikegami, H.; Ikeda, M.; Kurimoto, M. Cloning and expression of interleukin-18 binding protein. FEBS. Lett. 445, 338-342 (1999).

57) Novick, D.; Kim, S. H.; Fantuzzi, G.; Reznikov, L. L.; Dinarello, C. A.; Rubinstein, M. Interleukin-18 binding protein: a novel modulator of the Th1 cytokine response. Immunity 10, 127-136(1999).

58) Hurgin, V.; Novick, D.; Rubinstein, M. The promoter of IL-18 binding protein: activation by an IFN-gamma -induced complex of IFN regulatory factor 1 and CCAAT/ enhancer binding protein beta. Proc. Natl. Acad. Sci. USA. 99, 16957-16962 (2002).

59) Harocopos, G. J.; Alvares, K. M.; Kolker, A. E.; Beebe, D. C. Human age-related cataract and lens epithelial cell death. Invest. Ophthalmol. Vis. Sci. 39, 26962706 (1998). 